\title{
Ensino de Ciências Ambientais rumo à profissionalização: uma análise cientométrica
}

\section{Environmental Sciences Teaching towards professionalization: a scientometric analysis}

\section{Enseñanza de Ciencias Ambientales hacia la profesionalización: un análisis cientométrica}

http://dx.doi.org/10.221713/2358-2332.2016.v14.1443

Otacilio Antunes Santana, doutor em Ciências Florestais pela Universidade de Brasília (UnB), professor do Departamento de Biofísica e Radiobiologia e do Mestrado Profissional em Rede Nacional para Ensino das Ciências Ambientais (ProfCiAmb), da Universidade Federal de Pernambuco (UFPE), Recife, PE, Brasil. E-mail: otacilio.santana@ufpe.br.

Clodoaldo de Lima, biólogo pela Universidade Federal de Pernambuco (UFPE), aluno do Mestrado Profissional em Rede Nacional para Ensino das Ciências Ambientais (ProfCiAmb) pela UFPE, Recife, PE, Brasil. E-mail: aldomblima@gmail.com.

Raquel Bernardo de Melo, geógrafa pela Universidade Federal de Pernambuco (UFPE), aluna do Mestrado Profissional em Rede Nacional para Ensino das Ciências Ambientais (ProfCiAmb) pela UFPE, Recife, PE, Brasil. E-mail: raquelbernardom@gmail.com.

Carla Valéria de Miranda Costa Duarte, bióloga pela Universidade Federal Rural de Pernambuco (UFRPE), aluna do Mestrado Profissional em Rede Nacional para Ensino das Ciências Ambientais (ProfCiAmb) pela UFPE, Recife, PE, Brasil. E-mail: carlavmcduarte @ hotmail.com.

Susana Carvalho de Souza, bióloga pela Universidade Federal de Pernambuco (UFPE), aluna do Mestrado Profissional em Rede Nacional para Ensino das Ciências Ambientais (ProfCiAmb) pela UFPE, Recife, PE, Brasil. E-mail: susana07@yahoo.com.br.

Mayara Lopes de Freitas Lima, graduanda em Ciências Biológicas - Licenciatura pela Universidade Federal de Pernambuco (UFPE), Recife, PE, Brasil. E-mail: mayfreitas18@gmail.com.

Izaquiel Doria Aragão, graduando em Ciências Biológicas - Licenciatura pela Universidade Federal de Pernambuco (UFPE), Recife, PE, Brasil. E-mail: izaquieldoria@ hotmail.com.

Jarcilene Silva Almeida Cortez, doutora em Biologia pela Universidade de Sherbrooke, Canadá, professora do Departamento de Botânica e do Mestrado Profissional em Rede Nacional para Ensino das Ciências Ambientais (ProfCiAmb), da Universidade Federal de Pernambuco (UFPE), Recife, PE, Brasil. E-mail: jacortez@ufpe.br.

\footnotetext{
${ }^{1}$ Como citar: ABNT NBR 6023:2002 e incluir o DOI.
} 
Santana et al. / Ensino de Ciências Ambientais rumo à profissionalização: uma análise cientométrica

\title{
Resumo
}

A profissionalização é um processo que implica a construção do fundamento epistemológico sobre a formação de atores envolvidos na produção de determinados serviços e produtos. Partindo dessa perspectiva, este trabalho objetivou resgatar as correntes filosóficas e ações pedagógicas norteadoras do processo de profissionalização do Ensino de Ciências Ambientais, mediante análise cientométrica sobre mais de 60 mil publicações extraídas de bases mundiais de informação e divulgação científica. Os dados obtidos revelaram que as publicações foram dinâmicas ao longo do tempo. A presença ou ausência do "homem na natureza" como forma de ação, e a sistematização de conceitos, direcionaram os caminhos lexicais e metodológicos das novas publicações, dando suporte literário, ao longo tempo, à dinâmica da formação do profissional das Ciências Ambientais.

Palavras-chave: Identidade Profissional. Bibliometria. Produtos Técnicos.

\begin{abstract}
Professionalization is a process that includes the construction of an epistemological basis for the formation of actors involved in the production of specific services and products. From this perspective, this study aimed to recover philosophical currents and pedagogical actions that guide the professionalization process on Environmental Sciences Teaching. Through a scientificometric analysis of more than 60,000 publications extracted from worldwide databases of scientific information and dissemination. Data obtained revealed that these publications were dynamic over time. The presence or absence of 'man in nature' as a form of action and systematization of concepts guided new publications' lexical and methodological paths, thus they supported, over time, the dynamics of the Environmental Sciences professional training.
\end{abstract}

Keyword: Professional Identity. Bibliometrics. Technical Products.

\section{Resumen}

La profesionalización es un proceso que implica la construcción de una base epistemológica para la formación de actores involucrados en la producción de servicios y productos específicos. Desde esta perspectiva, este trabajo tuvo como objetivo recuperar las corrientes filosóficas y las acciones pedagógicas que guían el proceso de profesionalización de la Enseñanza de Ciencias Ambientales, mediante un análisis cientométrico de más de 60,000 publicaciones extraídas de bases de datos mundiales de información y divulgación científica. Los datos obtenidos revelaron que las publicaciones fueron dinámicas a lo largo del tiempo. La presencia o ausencia del "hombre en la naturaleza" como forma de acción y la sistematización de conceptos guiaron los caminos lexicales y metodológicos de las nuevas publicaciones, dando soporte literario, a lo largo del tiempo, a la dinámica de la formación profesional de las Ciencias Ambientales.

Palabras clave: Identidad Profesional. Bibliometría. Productos Técnicos.

\section{INTRODUÇÃO}

A institucionalização de um pensamento, ou "a criação de ontos com limites abruptos", faz com que se perca a ideia originária sobre o abstrato ou o concreto institucionalizado (MÜLHMANN, 
Santana et al. / Ensino de Ciências Ambientais rumo à profissionalização: uma análise cientométrica

1961). A profissionalização, ou a construção de um profissional “ótimo", pode flertar com a delimitação de um indivíduo que age sob um determinado molde, formatado por competências e suas dimensões: a área de conhecimento e a sua técnica. Longe disso, e de maneira crítica, este trabalho objetivou não em delimitar, mas resgatar nos referenciais teóricos e no estado da arte as correntes filosóficas do educador rumo à profissionalização do Ensino de Ciências Ambientais, por meio de uma análise cientométrica. A partir desse resgate, para a discussão da identidade profissional, habilidades, atitudes, códigos éticos e produtos gerados foram analisados em relação às correntes filosóficas.

A construção de competências profissionais conceituadas na literatura é simplista, pois ela vai em direção aos limites legais de atuação profissional (qualificação e certificação), no sentido técnico e de execução das atividades técnicas (ARGYRIS; SCHON, 1974; EPSTEIN; HUNDERT, 2002). A formação de um profissional é complexa, pois, envolve as dimensões do conhecimento (téchne), da prática (práxis) e da sensibilidade (poiesis), elementos obrigatórios para a construção do sujeito contextualizado, engajado e emancipado, fruto de um processo de ensino e aprendizagem (FREIRE, 1996). Sob esse prisma, alcança-se o sujeito apetente, que difere do sujeito competente, pois o apetente é motivado a refletir e a solucionar problemas para além do que lhe é dado profissionalmente (SANTANA, 2014, 2016a; SANTANA; PADILHA, 2017; SANTANA; PETROVA, 2016).

No Brasil, a consolidação das discussões epistemológicas sobre o profissional da Educação (e do Ensino) é recente, e somente a partir de 2009 surgem os primeiros mestrados profissionais na área (AMBROSETTI; CALIL, 2016), embora a sistematização da atuação desse profissional venha sendo debatida desde a criação dos primeiros espaços educacionais (ASSMANN, 2003). Ademais, na apreensão do que é necessário saber, do saber fazer e do saber ser, o egresso advindo desses cursos com enfoque profissional se assemelha ao egresso dos mestrados acadêmicos, apesar dos discursos de criação apresentarem horizontes distintos (MOREIRA, 2004; MOREIRA; NARDI, 2009; SCARANO; OLIVEIRA, 2005). Por isso, é essencial retornar ao "fundamento" da modalidade do curso (OSTERMANN; REZENDE, 2009) e é o que este trabalho se propõe ao efetuar uma revisão de literatura, revisitando os fundamentos profissionais fruto da capacitação dos atores de uma determinada área de concentração: Ensino de Ciências Ambientais.

Nesse sentido, o percurso curricular de um profissional o direciona para a formação de um sujeito que, diante do seu objeto de investigação, sistematize determinados tipos de produtos, métodos ou serviços. Formar um educador necessita de um olhar holístico por parte do formador, ou seja, educar mirando o real de forma inteira, não fragmentada (CARVALHO, 2004; STEIL; CARVALHO, 2014). Quando esse educador tem como objeto de ensino, de aprendizado e de pesquisa, o conteúdo das Ciências Ambientais, o seu pensamento obrigatoriamente perpassa horizontes físicos (como variáveis ambientais, influências meteorológicas, biomassa das espécies etc.) e metafísicos (como culturas, tradições, religiões etc.). Por conseguinte, profissionalizar é construir conteúdos, atitudes e habilidades no sentido de congregar as várias áreas do conhecimento das Ciências Ambientais Ecologia, Biodiversidade, Qualidade Ambiental, Cultura e Sustentabilidade, Sobrevivência da Sociedade Humana - para, então, formar um sujeito participador e inserido no próprio objeto de estudo, que utiliza os produtos, métodos e serviços gerados (MILLER; SPOOLMAN, 2016).

A prática do profissional das Ciências Ambientais formado a partir dessas áreas do conhecimento o fez atuar naturalmente sob correntes filosóficas que foram sistematizadas por Sauvé (2010) - Biorregionalista, Científica, Conservacionista, Crítica, Ecoeducadora, Etnográfica, Feminista, Holística, Humanista, Moralista, Naturalista, Praxista, Sistêmica, Solucionadora e 
Sustentável. A delimitação dessas correntes foi apropriada pela literatura da área Ciências Ambientais, bem como replicadas pela mídia e pelo medium educational (KAUFMAN, 1972). É importante relatar aqui que, apesar dessa delimitação, as correntes filosóficas apresentam em algum momento interfaces (SAUVÉ, 2010).

A partir das apropriações literárias de determinados escopos (como as correntes filosóficas citadas), ferramentas de análise cientométrica foram criadas para sistematização de padrões e exceções na recuperação científica (como por termos de indexação) diante da quantidade de artigos, livros e capítulos de livros publicados e registrados nas bases de dados científicas. Essas ferramentas permitiram também a análise do impacto das publicações, ou de um conjunto delas, dado a sua qualidade, o seu valor agregado e a sua importância histórica (CHEN, 2017; CHEN et al., 2012). Com esses elementos, a cientometria pode ser definida como o estudo da mensuração e qualificação da dinâmica científica, baseada em indicadores bibliométricos (SILVA; BIANCHI, 2001; TAUBES, 1993).

Então, os objetivos específicos deste trabalho foram: i) recuperar as publicações nas bases de dados científicas; ii) fazer uma análise cientométrica dos trabalhos levantados pelo tempo; iii) separar as publicações pela aderência de seus escopos por corrente filosófica; iv) agrupar os trabalhos pelas dimensões profissionais utilizadas por seus atores: atitudes, habilidades e código de ética; v) quantificar os trabalhos que foram desdobramentos de aplicação de patente; tudo isso relacionado ao Ensino de Ciências Ambientais e a sua profissionalização.

\section{MÉTODOS E ANÁLISES}

A narrativa bibliométrica foi sistematizada para discussão da identidade profissional do educador em Ensino de Ciências Ambientais a partir das correntes filosóficas, dos produtos e dos serviços (Figura 1). O método utilizado é adequado ao objetivo deste trabalho por elucidar as convergências de escopos literários ao longo do tempo (LEYDESDORFF, 2017). Para tanto, a análise cientométrica foi realizada pela recuperação da informação científica, conforme a álgebra booleana - "e"; "ou”; “e não" (BOOLE, 1854), nas bases de dados: Google Scholar, Science Direct, Taylor \& Francis, Scielo, Scopus, PubMed e Web of Science, com a utilização dos termos de indexação: "ensino", "ciências ambientais" e "profissionalização", com suas possíveis variações ( "ciências da natureza", "educação", "aprendizagem", "profissional", e outros) e traduções a outros idiomas (inglês, francês, alemão e russo). Todos os trabalhos recuperados (artigos, capítulos de livros e livros) foram averiguados no que tange à temática e ao objetivo do trabalho. A análise cientométrica foi realizada com o programa CiteSpace, construído por Chen (CHEN, 2017; CHEN et al., 2012). Essa análise recuperou e agrupou as referências quanto a sua similaridade, dentro das bases de dados científicas, segundo os termos de indexação que algoritmicamente seguiram as correntes filosóficas do educador nas Ciências Ambientais, sistematizadas por Sauvé (2010; Quadro 1). 
Santana et al. / Ensino de Ciências Ambientais rumo à profissionalização: uma análise cientométrica

\section{Quadro 1 - Correntes filosóficas do educador nas Ciências Ambientais}

\begin{tabular}{|c|c|c|c|c|}
\hline Corrente & $\begin{array}{c}\text { Concepção de } \\
\text { ambiente }\end{array}$ & Objetivos & Saberes & Estratégias de ensino \\
\hline Biorregionalista & $\begin{array}{l}\text { i) Lugar de } \\
\text { pertencimento } \\
\text { ii) Projeto comunitário }\end{array}$ & $\begin{array}{l}\text { i) Desenvolver competências em } \\
\text { ecodesenvolvimento comunitário, } \\
\text { local ou regional }\end{array}$ & $\begin{array}{l}\text { i) Cognitivo } \\
\text { ii) Afetivo } \\
\text { iii) Experencial } \\
\text { iv) Pragmático } \\
\text { v) Criativo }\end{array}$ & $\begin{array}{l}\text { i) Exploração do meio } \\
\text { ii) Projeto comunitário } \\
\text { iii) Criação de } \\
\text { ecoempresas }\end{array}$ \\
\hline Científica & i) Objeto de estudo & $\begin{array}{l}\text { i) Adquirir conhecimentos em } \\
\text { Ciências Ambientais } \\
\text { ii) Desenvolver habilidades } \\
\text { relativas a experiencias científicas. }\end{array}$ & $\begin{array}{l}\text { i) Cognitivo } \\
\text { ii) Experimental }\end{array}$ & $\begin{array}{l}\text { i) Estudo de fenômenos } \\
\text { ii) Observação } \\
\text { iii) Demonstração } \\
\text { iv) Experimentação } \\
\text { v) Atividade de } \\
\text { investigação hipotético- } \\
\text { dedutiva }\end{array}$ \\
\hline Conservacionista & i) Recurso & $\begin{array}{l}\text { i) Adotar comportamentos de } \\
\text { conservação } \\
\text { ii) Desenvolver habilidades } \\
\text { relativas à gestão ambiental }\end{array}$ & $\begin{array}{l}\text { i) Cognitivo } \\
\text { ii) Pragmático }\end{array}$ & $\begin{array}{l}\text { i) Guia ou código de } \\
\text { comportamentos } \\
\text { ii) Auditoria ambiental } \\
\text { iii) Projeto de gestão em } \\
\text { conservação }\end{array}$ \\
\hline Crítica & $\begin{array}{l}\text { i) Objetos de } \\
\text { transformação } \\
\text { ii) Lugar de } \\
\text { emancipação }\end{array}$ & $\begin{array}{l}\text { i) Desenvolver as realidades socio- } \\
\text { ambientais em vista de } \\
\text { transformar o que causa problema }\end{array}$ & $\begin{array}{l}\text { i) Prático } \\
\text { ii) Reflexivo } \\
\text { iii) Dialógico }\end{array}$ & $\begin{array}{l}\text { i) Análise de discurso } \\
\text { ii) Estudos de caso } \\
\text { iii) Debate } \\
\text { iv) Investigação-ação }\end{array}$ \\
\hline Ecoeducadora & $\begin{array}{l}\text { i) Polo de interação } \\
\text { para a formação } \\
\text { pessoal } \\
\text { ii) Oficinas de } \\
\text { identidade }\end{array}$ & $\begin{array}{l}\text { i) Experimentar o meio ambiente } \\
\text { para formar "em" e "pelo" } \\
\text { ambiente } \\
\text { ii) Construir sua relação com o } \\
\text { mundo e com outros seres }\end{array}$ & $\begin{array}{l}\text { i) Experencial } \\
\text { ii) Sensorial } \\
\text { iii) Intuitivo } \\
\text { iv) Afetivo } \\
\text { v) Simbólico } \\
\text { vi) Criativo }\end{array}$ & $\begin{array}{l}\text { i) Relato de vida } \\
\text { ii) Imersão } \\
\text { iii) Exploração } \\
\text { iv) Introspecção } \\
\text { v) Escuta sensível } \\
\text { vi) Alternância } \\
\text { subjetiva/objetiva } \\
\text { vii) Jogos }\end{array}$ \\
\hline Etnográfica & $\begin{array}{l}\text { i) Território } \\
\text { ii) Lugar de } \\
\text { identidade, da } \\
\text { natureza e da cultura }\end{array}$ & $\begin{array}{l}\text { i) Reconhecer o estreito laço entre } \\
\text { natureza e cultura } \\
\text { ii) Clarificar sua própria } \\
\text { cosmologia } \\
\text { iii) Valorizar a dimensão cultural } \\
\text { de sua relação com o ambiente }\end{array}$ & $\begin{array}{l}\text { i) Experencial } \\
\text { ii) Intuitivo } \\
\text { iii) Afetivo } \\
\text { iv) Simbólico } \\
\text { v) Espiritual } \\
\text { vi) Criativo } \\
\text { vii) Estético }\end{array}$ & $\begin{array}{l}\text { i) Contos, narrações e } \\
\text { lendas } \\
\text { ii) Estudo de Caso } \\
\text { iii) Imersão }\end{array}$ \\
\hline Feminista & i) Objeto de aplicação & $\begin{array}{l}\text { i) Integrar aos valores feministas a } \\
\text { relação com o ambiente }\end{array}$ & $\begin{array}{l}\text { i) Intuitivo } \\
\text { ii) Afetivo } \\
\text { iii) Simbólico } \\
\text { iv) Espiritual } \\
\text { v) Criativo } \\
\text { vi) Estético }\end{array}$ & $\begin{array}{l}\text { i) Estudo do casos } \\
\text { ii) Imersão } \\
\text { iii) Oficina de criação } \\
\text { iv) Atividade de } \\
\text { intercâmbio e de } \\
\text { comunicação }\end{array}$ \\
\hline Holística & i) Ser/ o todo/ Gaia & $\begin{array}{l}\text { i) Desenvolver as múltiplas } \\
\text { dimensões do ser na interação com } \\
\text { o conjunto de dimensões do } \\
\text { ambiente } \\
\text { ii) Desenvolver um conhecimento } \\
\text { econômico do mundo e um atuar } \\
\text { participativo "em" e "com" o } \\
\text { ambiente }\end{array}$ & $\begin{array}{l}\text { i) Holístico } \\
\text { ii) Orgânico } \\
\text { iii) Intuitivo } \\
\text { iv) Criativo }\end{array}$ & $\begin{array}{l}\text { i) Exploração livre } \\
\text { ii) Visualização } \\
\text { iii) Oficinas de criação } \\
\text { iv) Integração de } \\
\text { estratégias } \\
\text { complementares }\end{array}$ \\
\hline Humanista & i) Meio de vida & $\begin{array}{l}\text { i) Conhecer seu meio de vida e } \\
\text { conhecer melhor a relação com } \\
\text { meio de vida } \\
\text { ii) Desenvolver um sentimento de } \\
\text { pertencimento }\end{array}$ & $\begin{array}{l}\text { i) Sensorial } \\
\text { ii) Cognitivo } \\
\text { iii) Afetivo } \\
\text { iv) Experencial } \\
\text { v) Criativo } \\
\text { vi) Estético }\end{array}$ & $\begin{array}{l}\text { i) Estudo do Meio } \\
\text { ii) Itinerário Ambiental } \\
\text { iii) Leitura da Paisagem }\end{array}$ \\
\hline Moralista & i) Objeto de valor & $\begin{array}{l}\text { i) Dar prova, ecocivismo } \\
\text { ii) Desenvolver um sistema ético }\end{array}$ & $\begin{array}{l}\text { i) Cognitivo } \\
\text { ii) Afetivo } \\
\text { iii) Moral }\end{array}$ & $\begin{array}{l}\text { i) Análise de valores } \\
\text { ii) Clarificação de } \\
\text { valores } \\
\text { iii) Crítica de valores } \\
\text { sociais }\end{array}$ \\
\hline
\end{tabular}


Santana et al. / Ensino de Ciências Ambientais rumo à profissionalização: uma análise cientométrica

\begin{tabular}{|c|c|c|c|c|}
\hline Naturalista & i) Natureza & $\begin{array}{l}\text { i) Reconstruir o laço com a } \\
\text { natureza }\end{array}$ & $\begin{array}{l}\text { i) Sensorial } \\
\text { ii) Experencial } \\
\text { iii) Afetivo } \\
\text { iv) Cognitivo } \\
\text { v) Criativo } \\
\text { vi) Estético }\end{array}$ & $\begin{array}{l}\text { i) Imersão } \\
\text { ii) Interpretação } \\
\text { iii) Jogos sensoriais } \\
\text { iv) Atividades de } \\
\text { descobrimento }\end{array}$ \\
\hline Praxista & $\begin{array}{l}\text { i) Oficinas de ação e } \\
\text { reflexão }\end{array}$ & $\begin{array}{l}\text { i) Aprender em, para e pela ação } \\
\text { ii) Desenvolver competências de } \\
\text { reflexão }\end{array}$ & i) Prático & i) Investigação-ação \\
\hline Sistêmica & i) Sistema & $\begin{array}{l}\text { i) Desenvolver o pensamento } \\
\text { sistêmico: análise e síntese sob } \\
\text { uma visão global } \\
\text { ii) Compreender as realidades } \\
\text { ambientais em direção de decisões } \\
\text { apropriadas }\end{array}$ & i) Cognitivo & $\begin{array}{l}\text { i) Estudo de caso: análise } \\
\text { de sistemas ambientais }\end{array}$ \\
\hline Solucionadora & i) Problema & $\begin{array}{l}\text { i) Desenvolver habilidades de } \\
\text { resolver problemas: do diagnóstico } \\
\text { à ação }\end{array}$ & $\begin{array}{l}\text { i) Cognitivo } \\
\text { ii) Pragmático }\end{array}$ & $\begin{array}{l}\text { i) Estudos de caso: } \\
\text { análise de soluções de } \\
\text { problemas } \\
\text { ii) Experiências de } \\
\text { solução de problema } \\
\text { associadas a um projeto }\end{array}$ \\
\hline Sustentável & $\begin{array}{l}\text { i) Recursos para o } \\
\text { desenvolvimento } \\
\text { econômico } \\
\text { ii) Recursos } \\
\text { compartilhados }\end{array}$ & $\begin{array}{l}\text { i) Promover um desenvolvimento } \\
\text { econômico respeitoso dos aspectos } \\
\text { sociais e do ambiente } \\
\text { ii) Contribuir ao desenvolvimento }\end{array}$ & $\begin{array}{l}\text { i) Cognitivo } \\
\text { ii) Pragmático }\end{array}$ & $\begin{array}{l}\text { i) Estudos de caso } \\
\text { ii) Experiências de } \\
\text { resolução de problemas } \\
\text { iii) Projetos de } \\
\text { desenvolvimento } \\
\text { sustentável }\end{array}$ \\
\hline
\end{tabular}

Fonte: Adaptado pelos autores de Sauvé (2010).

Em seguida, as publicações resgatadas e agrupadas a partir da corrente filosófica foram correlacionadas com tendências para as atitudes, as habilidades e em relação ao código ético na conduta de ação profissional - deontologia e teleologia. Os conceitos tomados para este trabalho na direção do profissional educador nas Ciências Ambientais foram: i) atitude - comportamento habitual que se verifica em circunstâncias diferentes; e, para área temática em questão, as atitudes profissionais preponderantes foram: a mobilização (criar identidades e objetivos em comum), a ação (diante de alguma demanda), o diagnóstico (análise das variáveis pós-fato) e a teórica (construção histórica a partir de sínteses) (COUSO, 2005; LEFF, 2001); ii) habilidade - destreza em analisar, remediar e experimentar na ação possível da área temática (GRANGEAT; GRAY, 2007; MILLER; SPOOLMAN, 2016; SILVA; ALMEIDA; GATTI, 2016); iii) deontologia - atuar de forma a seguir um código específico, um protocolo, um método de ensino; e iv) teleologia - atuar rumo a uma finalidade (BAGNALL; HODGE, 2017; VEIGA; KAPUZINIAK; ARAÚJO, 2005). 


\section{Figura 1 - Caminho metodológico para análise cientométrica}

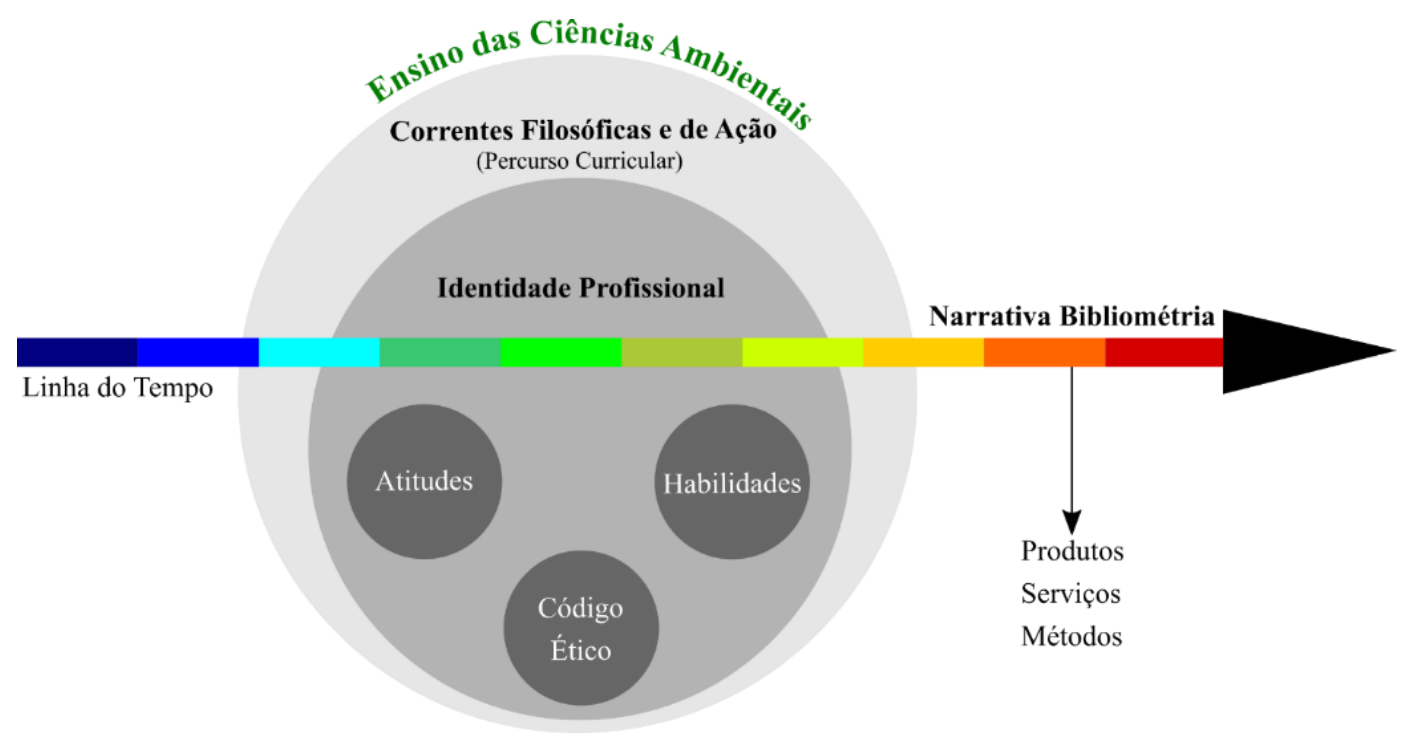

Fonte: Elaborado pelos autores.

O ordenamento por eixo foi realizado por Análise de Correspondência Canônica, levando em consideração a frequência dos termos de indexação por corrente filosófica do educador nas Ciências Ambientais (AKAIKE, 1976). Ao final, com as publicações recuperadas, foram analisados quantos geraram produtos e serviços em relação à classificação da propriedade intelectual e industrial (BRASIL, 1996), depositados na Organização Mundial da Propriedade Intelectual (World Intellectual Property Organization). A finalidade desse procedimento foi ressaltar o direcionamento das publicações que tendiam a um estudo profissional, que tem a objetividade da criação de um produto patenteável para atuação profissional. Um estudo puramente acadêmico não prioriza patentear produtos (Quadro 2).

\section{Quadro 2 - Propriedade industrial com possibilidade de registro de patente}

\begin{tabular}{ll}
\hline \multicolumn{1}{c}{ Patenteável } & \multicolumn{1}{c}{ Não Patenteável } \\
\hline I - Invenção e modelo de utilidade & IV - descobertas, teorias científicas e métodos matemáticos; \\
II - Desenho industrial & V - concepções puramente abstratas; \\
\hline III - Registro de marca & VI - esquemas, planos, princípios ou métodos comerciais, contábeis, financeiros, educativos, \\
& publicitários, de sorteio e de fiscalização; \\
& VII - as obras literárias, arquitetônicas, artísticas e científicas ou qualquer criação estética; \\
& VIII - programas de computador em si; \\
& IX - apresentação de informações; \\
& X - regras de jogo; \\
& XI - técnicas e métodos operatórios ou cirúrgicos, bem como métodos terapêuticos ou de \\
& diagnóstico, para aplicação no corpo humano ou animal; e \\
& XII - o todo ou parte de seres vivos naturais e materiais biológicos encontrados na natureza, \\
& ou ainda que dela isolados, inclusive o genoma ou germoplasma de qualquer ser vivo natural \\
& e os processos biológicos naturais \\
\hline
\end{tabular}

Fonte: Elaborado pelos autores a partir de Brasil (1996).

\section{RESULTADOS E DISCUSSÃO}

A quantidade de publicações recuperada sobre a temática da profissionalização no Ensino de Ciências Ambientais foi de 61.848 trabalhos (n). Essa quantidade acumulada de trabalhos resultou 
em um crescimento exponencial de publicações ao longo do tempo, analisado no CiteSpace (Figura 2A). Dos anos 1950 até as publicações mais recentes analisadas nesse trabalho, observa-se a influência das correntes filosóficas como eixo norteador da produção literária (Figura 2B).

Observa-se nos trabalhos pesquisados a dinâmica das escolhas feitas sobre uma ou outra corrente filosófica, considerando dois momentos históricos: i) até 1984, as correntes preponderantes foram a Científica, a Conservacionista, a Sustentável e a Ecoeducadora; e ii) a partir do século XXI, foram a Naturalista, a Humanista, a Bioregionalista, a Crítica, a Solucionadora e Feminista. Um período em que o processo de ensino e aprendizagem foi mais sistêmico e holístico (primeiro momento), e um período de determinação de conduta de ação (segundo momento). Essa variação histórica do escopo literário do enfoque de atuação profissional foi observada tanto no contexto da Educação (SAVIANI, 2003) quanto das Ciências Ambientais (ISENBERG, 2017).

Um crescimento quase linear dos trabalhos recuperados ao longo do tempo foi observado (Figura 2A) a partir da década de 1990. Nesse período, ocorreram dois eventos históricos importantes para a Ciências Ambientais, que foram a Cúpula da Terra - Rio-92, no Rio de Janeiro/Brasil (1992), e a Conferência das Partes 3 (COP 3), em Quioto/Japão (1997). A partir desses, devido à constatação de carência de informações sobre os temas abordados, as editoras estimularam a produção literária de conteúdos interdisciplinares relativos às Ciências Ambientais (ISENBERG, 2017).

Essa tendência de aumento foi até 2012, em que se verifica um ponto de inflexão para cima, conforme Figura 2A, indicando maior elevação do número de publicações por período. Nos últimos quatro anos (2013-2017), o número de publicações na temática pesquisada superou a quantidade de 18 mil trabalhos.

Com base na literatura pesquisada observaram-se dois motivos para explicar a tendência de crescimento das publicações. O primeiro motivo foi que os educadores e os pesquisadores (narradores da ação) tratavam de forma separada o ambiente (objeto do processo de ensino e aprendizagem) com a sociedade humana: o homem e a natureza. Antes da década de 1980, o papel do homem foi interpretar e intervir no ambiente (GRANGE, 1977). De forma significativa, a partir dessa década, tanto os educadores quanto os autores das publicações já descrevem ações do homem inserido na natureza, sem uma fragmentação (DELANEY, 2001). No processo de ensino e aprendizagem isso implicou em estratégias mais teóricas e imaginativas, no primeiro momento, e mais práticas e sensitivas a posteriori.

O segundo motivo foi a criação de conceitos (CHURCHILL JUNIOR, 1979). A cada conceito construído, alterava-se o rumo do estado da arte. Por exemplo, a partir da consolidação do conceito de "consumidor verde", na década de 1990 (MACKENZIE, 1990), tem-se registradas 9.427 publicações direcionadas especificamente com essa expressão no contexto do ensino e aprendizagem. Essa convergência histórica dos dois motivos apresentados ficou perceptível nos 25 trabalhos mais citados na revisão bibliométrica (Quadro 3), e não houve uma correlação entre o número de citações e a idade do artigo. 
Santana et al. / Ensino de Ciências Ambientais rumo à profissionalização: uma análise cientométrica

Figura 2 - Quantidade de publicações recuperadas nas bases de dados científicas

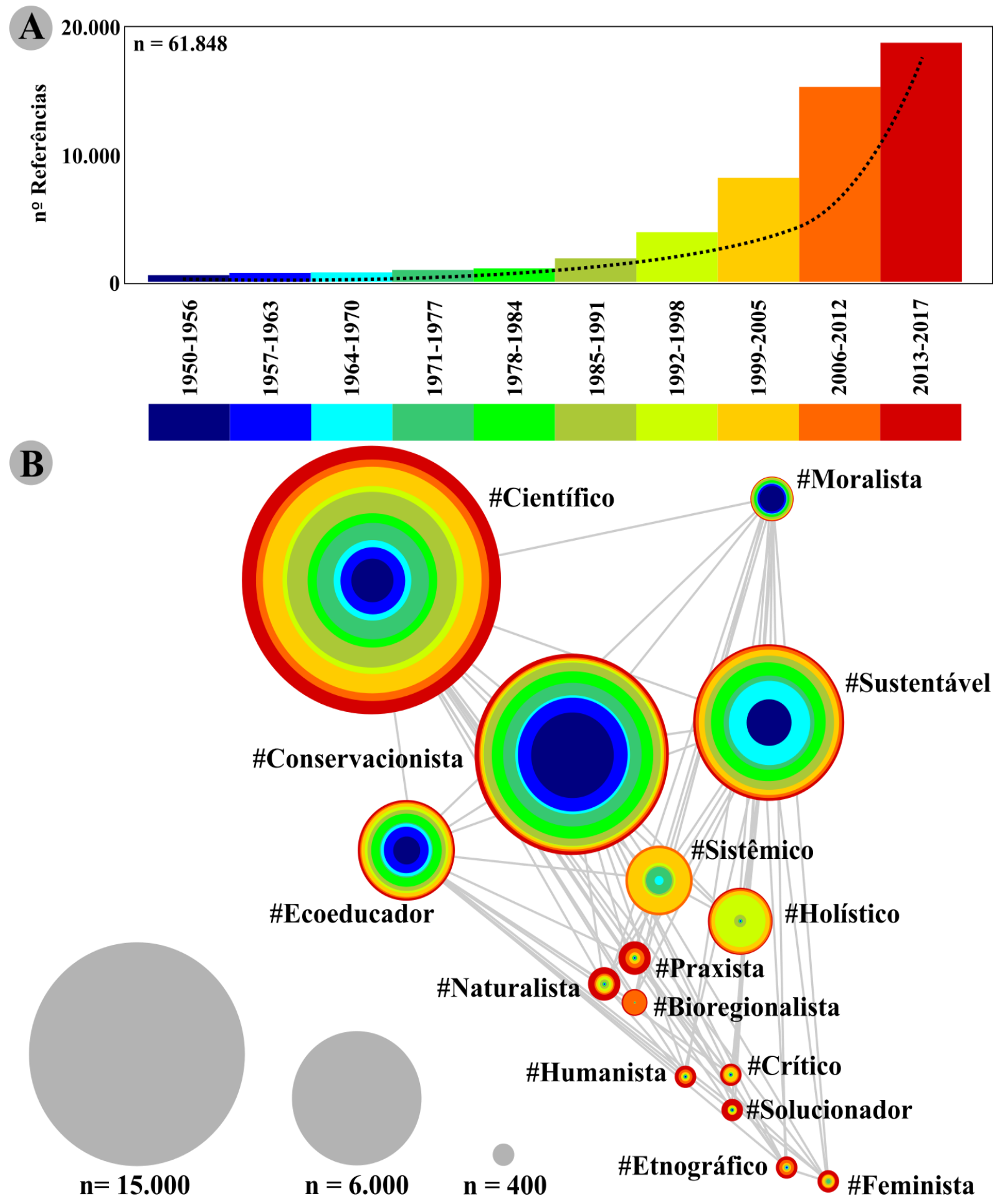

Fonte: Elaborado pelos autores.

Legenda: (A) Termos de indexação: "Ensino", "Ciências Ambientais" e "Profissionalização".

(B) Agrupadas por: correntes filosóficas do educador nas Ciências Ambientais. 
Santana et al. / Ensino de Ciências Ambientais rumo à profissionalização: uma análise cientométrica

\section{Quadro 3 - Artigos mais citados no tema da profissionalização do ensino nas Ciências Ambientais}

\begin{tabular}{|c|c|c|}
\hline Cita & no & Referências \\
\hline 634 & 002 & $\begin{array}{l}\text { OLLMUSS, A.; AGYEMAN, J. Mind the gap: why do people act environmentally and what are the barriers } \\
\text { pro-environmental behavior? Environmental Education Research, Abingdon, v. 8, p. 239-260, } 2002 . \\
\text { i: } 10.1080 / 13504620220145401\end{array}$ \\
\hline 3247 & 978 & $\begin{array}{l}\text { DUNLAP, R. E.; VAN LIERE, K. D. The "new environmental paradigm". The Journal of Environmental } \\
\text { Education, Abingdon, v. 9, p. 10-19, 1978. doi: 10.3200/JOEE.40.1.19-28 }\end{array}$ \\
\hline 2221 & 990 & $\begin{array}{l}\text { HUNGERFORD, H. R.; VOLK, T. L. Changing learner behavior through environmental education. The } \\
\text { Journal of Environmental Education, Abingdon, v. 21, n. 3, p. 8-21, 1990. doi: } \\
10.1080 / 00958964.1990 .10753743\end{array}$ \\
\hline 1201 & 2002 & $\begin{array}{l}\text { PALMER, J. Environmental education in the 21st century: theory, practice, progress and promise. London: } \\
\text { Routledge, } 2002 .\end{array}$ \\
\hline 917 & 998 & $\begin{array}{l}\text { CHAWLA, L. Significant life experiences revisited: a review of research on sources of environmental } \\
\text { sensitivity. The Journal of Environmental Education, Abingdon, v. 29, p. 11-21, 1998. doi: } \\
10.1080 / 1350462980040402\end{array}$ \\
\hline 768 & 001 & $\begin{array}{l}\text { RICKINSON, M. Learners and learning in environmental education: a critical review of the } \\
\text { evidence. Environmental Education Research, Abingdon, v. 7, p. 207-320, 2001. doi: } \\
10.1080 / 13504620120065230\end{array}$ \\
\hline 655 & 995 & $\begin{array}{l}\text { TILBURY, D. Environmental education for sustainability: defining the new focus of environmental education } \\
\text { in the 1990s. Environmental Education Research, Abingdon, v. 1, n. 2, p. 195-212, 1995. doi: } \\
10.1080 / 1350462950010206\end{array}$ \\
\hline 613 & 1980 & $\begin{array}{l}\text { TANNER, T. Significant life experiences: a new research area in environmental education. The Journal of } \\
\text { Environmental Education, Abingdon, v. 11, p. } 20-24,1980 \text {. doi: } 10.1080 / 00958964.1980 .9941386\end{array}$ \\
\hline 542 & 1980 & $\begin{array}{l}\text { HUNGERFORD, H.; PEYTON, R. B.; WILKE, R. J. Goals for curriculum development in environmental } \\
\text { education. The Journal of Environmental Education, Abingdon, v. 11, p. 42-47, 1980. doi: } \\
10.1080 / 00958964.1980 .9941381\end{array}$ \\
\hline 506 & 2007 & $\begin{array}{l}\text { CHAWLA, L.; CUSHING, D. F. Education for strategic environmental behavior. Environmental Education } \\
\text { Research, Abingdon, v. 13, p. 437-452, 2007. doi: 10.1080/13504620701581539 }\end{array}$ \\
\hline 486 & 2007 & $\begin{array}{l}\text { STEVENSON, R. B. Schooling and environmental education: contradictions in purpose and } \\
\text { practice. Environmental Education Research, Abingdon, v. 13, p. 139-153, 2007. doi: } \\
10.1080 / 13504620701295726\end{array}$ \\
\hline 438 & 1982 & $\begin{array}{l}\text { ALBRECHT, D. et al. Measuring environmental concern: the new environmental paradigm scale. The } \\
\text { Journal of Environmental Education, Abingdon, v. 13, p. 39-43, } 1982 \text {. do: } \\
10.1080 / 00958964.1982 .9942647\end{array}$ \\
\hline
\end{tabular}

4092002 JENSEN, B. B. Knowledge, action and pro-environmental behaviour. Environmental Education Research, Abingdon, v. 8, p. 325-334, 2002. doi: 10.1080/13504620220145474

\begin{tabular}{|c|c|c|}
\hline 407 & 1989 & $\begin{array}{l}\text { IOZZI, L. A. What research says to the educator part two: environmental education and the affective } \\
\text { domain. The Journal of Environmental Education, Abingdon, v. 20, p. 6-13, 1989. doi: } \\
10.1080 / 00958964.1989 .9943033\end{array}$ \\
\hline 315 & 1993 & $\begin{array}{l}\text { PALMER, J. A. Development of concern for the environment and formative experiences of educators. The } \\
\text { Journal of Environmental Education, Abingdon, v. 24, p. 26-30, } 1993 \text {. doi: } \\
10.1080 / 00958964.1993 .9943500\end{array}$ \\
\hline 257 & 1986 & $\begin{array}{l}\text { utdoor education: a matter of many relationships. The Journal of Environmental } \\
\text { 17, p. 13-15, 1986. doi: } 10.1080 / 00958964.1986 .9941413\end{array}$ \\
\hline 255 & 1996 & $\begin{array}{l}\text { BALLANTYNE, R. R.; PACKER, J. M. Teaching and learning in environmental education: developing } \\
\text { environmental conceptions. The Journal of Environmental Education, Abingdon, v. 27, p. 25-32, } 1996 . \\
\text { doi: 10.1080/00958964.1996.9941455 }\end{array}$ \\
\hline 237 & 2005 & $\begin{array}{l}\text { SAUVÉ, L. Currents in environmental education: mapping a complex and evolving pedagogical } \\
\text { field. Canadian Journal of Environmental Education, Sydney, v. 10, p. 11-37, } 2005 . \\
\text { https://cjee.lakeheadu.ca/article/view/175 }\end{array}$ \\
\hline
\end{tabular}

SAUVÉ, L. Environmental education between modernity and postmodernity: searching for an integrating 1961999 educational framework. Canadian Journal of Environmental Education, Sydney, v. 4, n. 1, p. 9-35, 1999. https://cjee.lakeheadu.ca/article/view/317

1472002 teachers. International Journal of Science Education, Abingdon, v. 24, p. 1191-1200, 2002. doi: 10.1080/09500690210134866 
Santana et al. / Ensino de Ciências Ambientais rumo à profissionalização: uma análise cientométrica

ARMSTRONG, J. B.; IMPARA, J. C. The impact of an environmental education program on knowledge and 1991 attitude. The Journal of Environmental Education, Abingdon, v. 22, p. 36-40, 1991. doi:

10.1080/00958964.1991.9943060
FIEN, J. Teaching for a sustainable world: the environmental and development education project for teacher

128 education. Environmental Education Research, Abingdon, v. 1, p. 21-33, 1995. doi: $10.1080 / 1350462950010102$

VOLK, T. L.; HUNGERFORD, H. R.; TOMERA, A. N. A national survey of curriculum needs as perceived by professional environmental educators. The Journal of Environmental Education, Abingdon, v. 16, p. 10-19, 1984. doi: 10.1080/00958964.1984.9942696

621987 ROBOTTOM, I. M. Two paradigms of professional development in environmental education. The Environmentalist, Abingdon, v. 7, p. 291-298, 1987. doi: 10.1007/BF02240218

61

O'DONOGHUE, R.; RUSSO, V. Emerging patterns of abstraction in environmental education: a review of 2004 materials, methods and professional development perspectives. Environmental Education Research, Abingdon, v. 10, p. 331-351, 2004. doi: 10.1080/1350462042000258170

Fonte: Elaborado pelos autores.

Nota: Em ordem decrescente de citações, são apresentados os primeiros 25 artigos sobre o tema.

Na correlação entre: i) os trabalhos agregados pelas correntes filosóficas, e ii) as atitudes, as habilidades e os códigos éticos, foram observadas aderências na frequência dos termos de indexação (Figura 3). Essas aproximações foram certificadas pela leitura das publicações consultadas. No que diz respeito às atitudes profissionais para a docência em Ciências Ambientais (Figura 3A os autores defendem posições mais teóricas e diagnosticadoras para o processo de ensino e aprendizagem, tendentes às correntes como Bioregionalista, Científico, Conservacionista, Feminista, Holístico, Moralista, Praxista, Sistêmico e Sustentável, bem como àquelas mais atuantes e mobilizadoras em correntes como Etnográfico, Ecoeducador, Crítico, Humanista, Naturalista e Solucionador.

Em relação às habilidades profissionais (Figura 3B), educadores que pendem para as correntes Naturalista, Científica, Conservacionista, Solucionadora e Sustentável foram mais hábeis em analisar e experimentar do que os educadores que tendem às correntes Biorregionalista, Crítica, Ecoeducadora, Etnográfica, Feminista, Holística, Humanista, Moralista, Praxista e Sistêmica, que são mais aderentes a remediar questões e temáticas das Ciências Ambientais, comparativamente. Em relação aos códigos éticos (Figura 3C), os educadores que atuavam nas correntes Científica, Conservacionista, Solucionadora, Sustentável, Sistêmica, Ecoeducadora e Moralista se aproximaram mais de ações sob os códigos deontológicos, enquanto os adeptos das correntes Biorregionalista, Crítica, Etnográfica, Feminista, Holística, Humanista, Naturalista e Praxista foram os que mais assumiram ações sob os códigos teleológicos.

Construir o sujeito com apetências nas diversas atitudes, habilidades e ética é o percurso para compreensão do papel das Ciências Ambientais em relação: i) aos contextos espaciais, temporais, sociais e culturais; ii) aos processos que envolvam extração e exploração da natureza; e iii) às demandas sociais, políticas e espirituais (PHILIPPI JUNIOR.; TUCCI; HOGAN, 2000; LEFF, 2011; JICKLING; STERLING, 2017). Por isso, a construção da identidade do educador em Ciências Ambientais deve transitar inter e transdisciplinarmente pelas correntes filosóficas, em termos institucionais (currículo) e profissionais (com automotivação, autodisciplina e autonomia) (ISENBERG, 2017).

A maioria dos métodos, serviços e produtos desenvolvidos para o Ensino de Ciências Ambientais apresentados nas publicações não foi patenteado ( $92 \%$, Figura 4A). Porém, ao longo do tempo, a relação entre patenteados e não patenteados vem aumentando. No último período avaliado 
(2013-2017), 34\% dos produtos apresentados nas publicações foram patenteados (Figura 4B). A atuação dos educadores de alguma das seguintes correntes filosóficas: Sistêmica, Solucionadora, Praxista e Holística, geraram mais patentes (Figura 4C). Na análise da produção literária, os autores dessas quatro correntes, pela concepção e natureza delas, preocuparam-se ou por uma demanda do sistema do capital ou por pertencimento a um grupo (como grupo de cientistas) e patentearam seus produtos, sobretudo seguindo um processo de reificação da natureza (QUINE, 1992). Se, por um lado, isso pode suscitar críticas, por outro, a sistematização de métodos e serviços, assim como o registro de produtos naturais, podem proteger a comunidade e biodiversidade local do sistema de futuras “quebras de patentes" ou pagamento de royalties (JAYARAMAN, 1996). Na construção do educador em Ciências Ambientais, essa dialética é fundamental para a reflexão acerca de questões sobre qual produto ambiental deve ser patenteado e para qual público se voltará (SANTANA, 2016b).

Figura 3 - Correlação canônica das correntes filosóficas

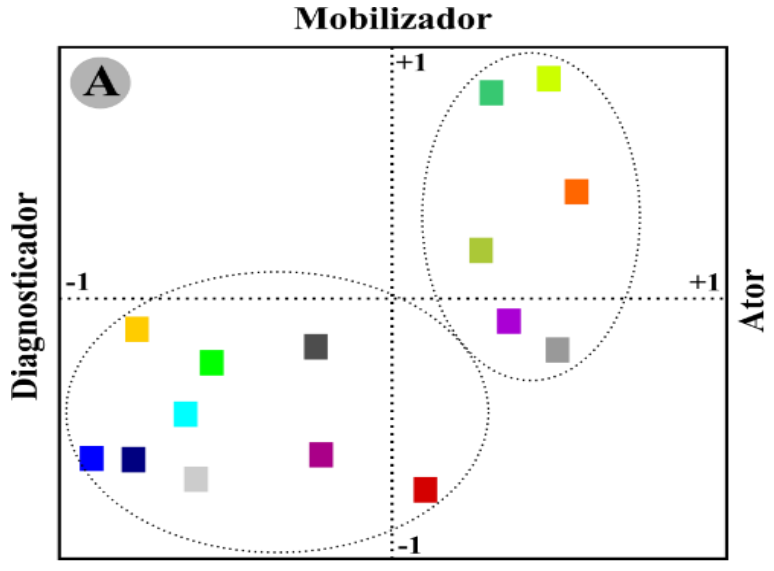

Teórico

Teleológico



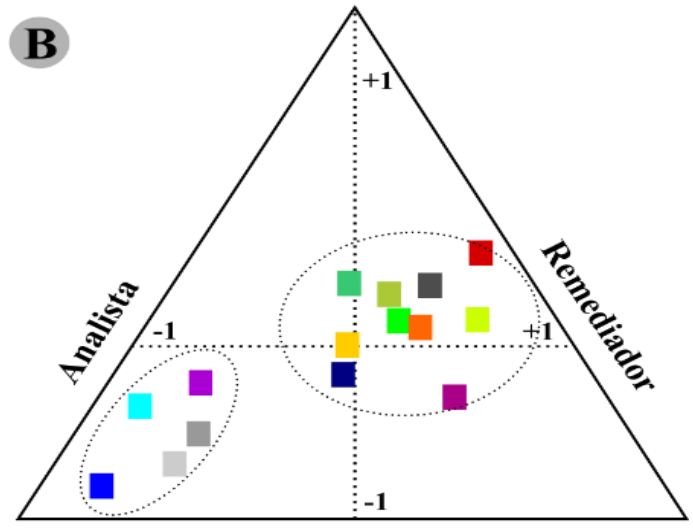

Experimentador

\begin{tabular}{l}
\hline \#Bioregionalista \\
\#Científico \\
\#Conservacionista \\
\#Crítico \\
\#Ecoeducador \\
\#Etnográfico \\
\#Feminista \\
\#Holístico \\
\#Humanista \\
\#Moralista \\
\#Naturalista \\
\#Praxista \\
\#Sistêmico \\
\#Solucionador \\
\#Sustentável
\end{tabular}

Fonte: Elaborado pelos autores.

Legenda: (A) Atitudes profissionais do educador na profissionalização do Ensino de Ciências Ambientais.

(B) Habilidades profissionais do educador na profissionalização do Ensino de Ciências Ambientais.

(C) Conduta ética na ação do educador na profissionalização do Ensino de Ciências Ambientais. 
Santana et al. / Ensino de Ciências Ambientais rumo à profissionalização: uma análise cientométrica

Figura 4 - Número de registros de patentes presentes na literatura avaliada
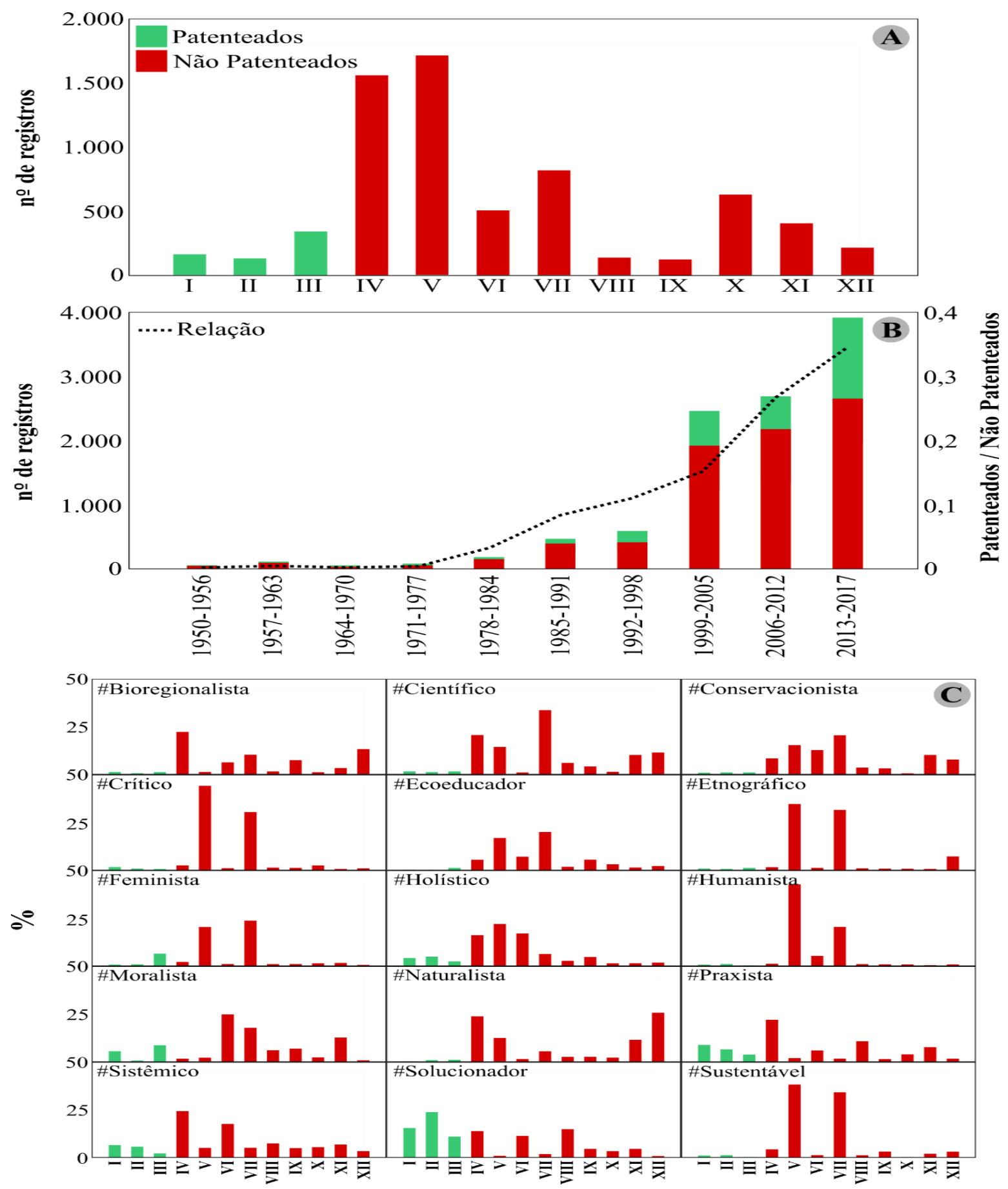

Fonte: Elaborado pelos autores.

Legenda: (A) Número de registros de produtos e ações Patenteados ( $\square$ ): I - Invenção e Modelo de Utilidade; II - Desenho Industrial; e III - Registro de marca; e Não Patenteados ( $\square$ ): IV - descobertas, teorias científicas e métodos matemáticos; $\mathrm{V}$ - concepções puramente abstratas; VI - esquemas, planos, princípios ou métodos comerciais, contábeis, financeiros, educativos, publicitários, de sorteio e de fiscalização; VII - as obras literárias, arquitetônicas, artísticas e científicas ou qualquer criação estética; VIII - programas de computador em si; IX - apresentação de informações; X - regras de jogo; XI - técnicas e métodos operatórios ou cirúrgicos, bem como métodos terapêuticos ou de diagnóstico, para aplicação no corpo humano ou animal; e XII - o todo ou parte de seres vivos naturais e materiais biológicos encontrados na natureza, ou ainda que dela isolados, inclusive o genoma ou germoplasma de qualquer ser vivo natural e os processos biológicos naturais, nos artigos recuperados. (B) Número de registros de produtos e ações patenteados e não patenteados ao longo das publicações por ano, e (C) sua relação por correntes filosóficas do educador nas Ciências Ambientais. 
Santana et al. / Ensino de Ciências Ambientais rumo à profissionalização: uma análise cientométrica

\section{CONSIDERAÇÕES FINAIS}

A análise cientométrica foi um eficiente método para o início de uma discussão sobre o Ensino de Ciências Ambientais a partir do objeto principal de estudo a ser analisado: o educador a caminho da sua profissionalização. As publicações recuperadas tiveram aderência às correntes filosóficas que emergiram e se consolidaram ao longo da construção epistemológica das Ciências Ambientais. Foi recuperado um amplo volume de publicações (>60.000) que puderam contribuir para a identificação do tipo de profissional que está sendo formado. Os caminhos léxico e metodológico das publicações foram dinâmicos ao passar do tempo, devido principalmente à separação física do homem da natureza em algumas correntes, e como ele agia a partir da relação homem-natureza. Essas tendências influenciaram na atuação do profissional ao longo do tempo: educador das Ciências Ambientais que tem atitudes, habilidades e ações sob códigos de ética conforme seu engajamento nas correntes filosóficas.

Outro viés na identificação do profissional em questão foi o produto, serviço ou método construído ao longo de sua formação, e se foi depositado em um banco de patentes. Essa identificação é fundamental para antagonizar os mestrados acadêmicos e profissionais em Ensino de Ciências Ambientais. Algumas correntes filosóficas na área do conhecimento estudada depositaram mais patentes por sua natureza, e, de forma ambivalente, a reificar e a proteger os recursos naturais para a sociedade local. O número de patentes aumentou em relação a produtos, métodos e serviços, a evidenciar a ambivalência citada. Sob outras narrativas e fundamentos, a convergência, a divergência e o diálogo com esse trabalho poderão surgir e serão necessários para um direcionamento conceitual do Ensino de Ciências Ambientais rumo à profissionalização.

\section{Referências}

AKAIKE, H. Canonical correlation analysis of time series and the use of an information criterion. Mathematics in Science and Engineering, Amsterdam, v. 126, p. 27-96, 1976. doi: 10.1016/S00765392(08)60869-3

AMBRosetTI, N. B.; CALIL, A. M. G. C. Contribuições do Mestrado Profissional em Educação para a formação docente. Revista Reflexão e Ação, Santa Cruz do Sul, v. 24, p. 85-104, 2016. doi: 10.17058/rea.v24i3.7526

ARGYRIS, C.; SCHON, D. A. Theory in practice: increasing professional effectiveness. Oxford: Jossey-Bass, 1974.

ASSMANN, J. The mind of Egypt: history and meaning in the time of the pharaohs. Cambridge: Harvard University Press, 2003.

BAGNALL, R. G.; HODGE, S. Using an epistemological perspective to understand competencebased vocational and professional education. In: Mulder, M. (Ed.). Competence-based vocational and professional education: bridging the worlds of work and education. New York: Springer, 2017. p. 125-144. 
Santana et al. / Ensino de Ciências Ambientais rumo à profissionalização: uma análise cientométrica

BRASIL. Lei ${ }^{\circ}$ 9.279, de 14 de maio de 1996. Regula direitos e obrigações relativos à propriedade industrial. Diário Oficial da União, Brasília, DF, 15 maio 1996. Seção 1. p. 8353. Disponível em: <https://goo.gl/F2qF0>. Acesso em: 14 abr. 2017.

BOOLE, G. An investigation of the laws of thought: on which are founded the mathematical theories of logic and probabilities. Cork: Dover Publications, 1854. Disponível em: <https://goo.g1/BPWuG2>. Acesso em: 14 abr. 2017.

CARVALHO, I. C. M. Educação ambiental: a formação do sujeito ecológico. São Paulo, Cortez. 2004.

CHEN, C. et al. Emerging trends in regenerative medicine: a scientometric analysis in CiteSpace.

Expert Opinion on Biological Therapy, London, v. 12, p. 593-608, 2012. doi: $10.1517 / 14712598.2012 .674507$

CHEN, C. Science Mapping: A systematic review of the literature. Journal of Data and Information Science, Berlin, v. 2, p. 1-33, 2017. doi: 10.1515/jdis-2017-0006

CHURCHILL JUNIOR, G. A. A paradigm for developing better measures of marketing constructs. Journal of Marketing Research, Birmingham, v. 16, n. 1, p. 64-73, 1979. doi: 10.2307/3150876

COUSO, D. La comunidad de aprendizaje profesional: una propuesta socioconstructivista de desarrollo profesional del profesorado de ciencias naturales. In: PERAFÁN, G. A.; ADÚRIZBRAVO, A. (Ed.). Pensamiento y conocimiento de los profesores. Bogotá: Editorial Nomos, 2005. p. 81-100.

DELANEY, D. Making nature/marking humans: law as a site of (cultural) production. Annals of the Association of American Geographers, Hoboken, v. 91, n. 3, p. 487-503, 2001. doi: 10.1111/00045608.00255

EPSTEIN, R. M.; HUNDERT, E. M. Defining and assessing professional competence. JAMA, Chicago, v. 287, p. 226-235, 2002. doi: 10.1001/jama.287.2.226

FREIRE, P. Pedagogia da autonomia: saberes necessários à prática pedagógica. São Paulo: Paz e Terra, 1996.

GRANGEAT, M.; GRAY, P. Factors influencing teachers' professional competence development. Journal of Vocational Education \& Training, Abingdon, v. 59, p. 485-501, 2007. doi: $10.1080 / 13636820701650943$

GRANGE, J. On the way towards foundation Ecology. Soundings: An Interdisciplinary Journal, University Park, PA, v. 60, n. 2, p. 135-149, 1977.

ISENBERG, A. C. Environmental history. Oxford: Oxford University Press, 2017.

JAYARAMAN, K. S. “Indian ginseng” brings royalties for tribe. Nature, London, v. 381, n. 6579, p. 182, 1996. doi: 10.1038/381182b0

JICKLING, B.; STERLING, S. (Ed.). Post-sustainability and environmental education: remaking education for the future. London: Palgrave Mcmillan, 2017. 
Santana et al. / Ensino de Ciências Ambientais rumo à profissionalização: uma análise cientométrica

KAUFMAN, R. A. Educational system planning. Ann Arbor: Prentice-Hall, 1972.

LEFF, E. Saber ambiental: sustentabilidade, racionalidade, complexidade, poder. Petrópolis: Vozes, 2001.

LEYDESDORFF, L. In praise of bibliometrics. Journal of Informetrics, Amsterdam, v. 11, n. 2, p. 595-597, 2017. doi: 10.1016/j.joi.2017.03.002

LEFF, E. Complexidade, interdisciplinaridade e saber ambiental. Olhar de Professor, Ponta Grossa, v. 14, n. 2, p. 309-335, 2011. doi: 10.5212/OlharProfr.v.14i2.0007

MACKENZIE, D. The green consumer. Food Policy, Amsterdam, v. 15, n. 6, p. 461-466, 1990. doi: 10.1016/0306-9192(90)90036-Y

MILLER, G. T.; SPOOLMAN, S. E. Ciência ambiental. Rio de Janeiro: Cengage Learning. 2016.

MOREIRA, M. A. O mestrado (profissional) em ensino. Revista Brasileira de Pós-Graduação, v. 1, n. 1, p. 131-142, 2004. doi: 10.21713/2358-2332.2004.v1.26

MOREIRA, M. A.; NARDI, R. O mestrado profissional na área de Ensino de Ciências e Matemática: alguns esclarecimentos. Revista Brasileira de Ensino de Ciência e Tecnologia, Ponta Grossa, v. 2, n. 3, p. 1-9. 2009. doi: 10.3895/S1982-873X2009000300001

MÜLHMANN, J. Messianismes révolutionnaires dans le tiers monde. Paris: Les Éditions de Minuit, 1961.

OSTERMANN, F.; REZENDE, F. Projetos de desenvolvimento e de pesquisa na área de ensino de ciências e matemática: uma reflexão sobre mestrados profissionais. Caderno Brasileiro de Ensino de Física, Florianópolis, v. 26, n. 1, p. 66-80, 2009. doi: 10.5007/2175-7941.2009v26n1p66

PHILIPPI JÚNIOR., A. et al. Interdisciplinaridade em Ciências Ambientais. São Paulo: Signus Editora, 2000.

QUINE, W. V. Structure and nature. The Journal of Philosophy, Charlottesville, v. 89, n. 1, p. 5-9, 1992. doi: $10.2307 / 2026889$

SAUVÉ, L. Educación científica y educación ambiental: un cruce fecundo. Enseñanza de las Ciencias: Revista de Investigación y Experiencias Didácticas, Barcelona, v. 28, n. 1, p. 5-18, 2010.

SANTANA, O. A. Observação da prática docente: um método para Licenciatura. Olinda: Livro Rápido, 2014. doi: 10.12702/978-85-406-0942-6

SANTANA, O. A. Evasão nas Licenciaturas das universidades federais: entre a apetência e a competência. Educação, Santa Maria, v. 41, n. 2, p. 311-327, 2016a. doi: 10.5902/1984644420199

SANTANA, O. A. Resistência social na Caatinga árida: a narrativa de quem ficou no colapso ambiental. Desenvolvimento e Meio Ambiente, Curitiba, v. 38, p. 419-438, 2016b. doi: 10.5380/dma.v38i0.43574

SANTANA, O. A.; PETROVA, Y. Ludicidade no ensino da normalidade em um ambiente florestal. Inter-Ação, Goiânia, v. 41, n. 3, p. 525-544, 2016. doi: 10.5216/ia.v41i3.41502 
Santana et al. / Ensino de Ciências Ambientais rumo à profissionalização: uma análise cientométrica

SANTANA, O. A.; PADILHA, M. A. S. Tutor EAD e o processo da tutoria na Universidade Aberta do Brasil. São Paulo: Blucher, 2017. doi: 10.5151/9788580393019

SAVIANI, D. Pedagogia histórico-crítica: primeiras aproximações. Campinas: Autores Associados, 2003.

STEIL, C. A.; CARVALHO, I. C. M. Epistemologias ecológicas: delimitando um conceito. Mana, Rio de Janeiro, v. 20, n. 1, p. 163-183, 2014. doi: 10.1590/S0104-93132014000100006

SCARANO, F. R.; OLIVEIRA, P. E. A. M. Sobre a importância da criação de mestrados profissionais na área de ecologia e meio ambiente. Revista Brasileira de Pós-Graduação, Brasília, DF, v. 2, n. 4, p. 90-96, 2005. doi: 10.21713/2358-2332.2005.v2.81

SILVA, J. A.; BIANCHI, M. L. P. Cientometria: a métrica da ciência. Paidéia, Ribeirão Preto, v. 11, n. 21, p. 5-10, 2001. doi: 10.1590/S0103-863X2001000200002

SILVA, V. G.; ALMEIDA, P. C. A.; GATTI, B. A. Referentes e critérios para a ação docente. Cadernos de Pesquisa, São Paulo, v. 46, n. 160, p. 286-311, 2016. doi: 10.1590/198053143415

TAUBES, G. Measures for measure in science. Science, Washington, DC, v. 260, p. 884-886, 1993.

VEIGA, I. P. A.; KAPUZINIAK, C.; ARAÚJO, J. C. S. Docência: uma construção ético-profissional. Campinas: Papirus, 2005.

Recebido em 03/07/2017

Aprovado em 22/11/2017 